\title{
POSSIBLE PROTECTIVE POTENTIAL OF ATORVASTATIN AND BLACK SEED (NIGELLA SATIVA) OIL IN AMIKACIN-INDUCED NEPHROTOXICITY IN ADULT MALE ALBINO RATS
}

\author{
Khaled A. Bayoumi ${ }^{1,2}$, Amani Abdel Fattah ${ }^{1}$ and Iman F. Gaballah ${ }^{1}$ \\ 1- Department of Forensic Medicine and Clinical Toxicology, Faculty of Medicine, Cairo \\ University, Cairo, Egypt. \\ 2- Department of Pathology, Faculty of Medicine, King Abdulaziz University, Jeddah, Saudi \\ Arabia.
}

\section{ABSTRACT}

Background and Objectives: Amikacin (AMK) has long been utilized as a gainful antibiotic in preventing Gram-negative infections. Despite all the profitable impacts, amikacin has significant nephrotoxic side effects. The possible protective effects of atorvastatin (ATO) and/or black seed (Nigella sativa) oil (NSO) were evaluated in rats with amikacin-induced acute renal damage, in which generation of reactive oxygen species plays a noteworthy role. Methods: Rats were treated with AMK (30 mg/kg body weight/day, subcutaneously) alone or with ATO $(5 \mathrm{mg} / \mathrm{kg} / \mathrm{day}$, by gavage) and/or NSO (400 mg/kg/day, by gavage) for 2 weeks. Nephrotoxicity was assessed using serum parameters in addition to tissue biomarkers of oxidative stress as well as renal histopathology. Results: Rats insulted with AMK showed increased serum creatinine and blood urea nitrogen. Besides, AMK significantly decreased the antioxidant capacity as reflected by the change in levels of malondialdehyde (MDA) and activities of reduced glutathione (GSH) and catalase (CAT) in the study. This was supported by the presence of marked morphological alterations of the kidney. Whereas pre-treatment with NSO alone protected the rats from AMKinduced renal toxicity, the nephroprotective effects of NSO-ATO combination were more potent than either of the two drugs alone. The simultaneous use of atorvastatin and NS oil resulted in a significant improvement of the above parameters of kidney functions and markers of oxidative stress as well as attenuation of histopathological alterations. Interpretation and Conclusion: Taken together, the present results indicate that the combination of ATO and NSO significantly minimizes AMK-induced nephrotoxicity in albino rats, may be due to their antioxidant properties.

Key Words: Amikacin; Atorvastatin; Nigella sativa; Nephrotoxicity; Antioxidants.

\section{INTRODUCTION:}

Aminoglycosides are highly effective antimicrobial agents since the introduction of streptomycin in 1944. They are used for the treatment of severe aerobic gram-ve infections and act synergistically against certain gram+ve organisms (Swan and Kaplan-Machlis, 1999). Most injected aminoglycosides are excreted in urine unmetabolized but $15 \%$ of the filtered load binds to megalin; a multi-ligand receptor expressed in high levels in proximal convoluted tubular cells (including S1 and S2 segments). It is then followed by their reuptake to the inner part of the tubular cells where they remain for a long period leading to renal affection (pathological and functional impairment of plasma membrane, mitochondria and lysosome) (Jadhav et al., 2019). Aminoglycosides help produce massive amounts of hydrogen peroxide by the renal cortex inhibiting synthesis of phospholipases A2 and glutathione in rats (Soejima et al., 2000). The ratio of free radical generating to scavenging enzymes may be deranged with apprehension of signal transduction cascade and disturbance of membrane phospholipids increasing cellular permeability. Studies have shown the ability of gentamicin (GM) to raise the generation of ROS metabolites; producing cellular injury and necrosis through peroxidation of membrane lipids, protein oxidation, and DNA damage (Jadhav et al., 2019).

Aminoglycoside-induced nephrotoxicity is characterized by proximal convoluted tubule cell necrosis with minor morphological changes in glomerular structures. Amikacin (AMK) is the most favoured due to its potent bactericidal effects, low resistance, 
synergistic actions with $\beta$-lactam antibiotics, and being inexpensive. Shockingly, AMK exerts intense renal toxic effects even with the lowest of doses which may terminate in acute renal failure (Wargo and Edwards, 2014).

Atorvastatin (ATO) is a generally and broadly recommended 3-hydroxy-3methylglutaryl coenzyme (HMG-CoA) reductase inhibitor that treats hyperlipidemia and lowers cholesterol (Jabarpour et al., 2020). Statin therapy, besides cardio protective effect, it also builds up a nephroprotective effect in pre-dialysis chronic renal illnesses and in renal transplantation. They also owe pleiotropic non-lipid dependent impacts including anti-inflammatory and antioxidant effects, suppression of extracellular matrix production and improvements in endothelial function. By inhibiting cholesterol biosynthesis pathway, statins impede Rho and Ras guanosine triphosphatases. Following statin therapy, renal antioxidant effects with consequent endothelial function regulation of renal vasculature may likewise help against nephrotoxicity (Jaikumkao et al., 2016).

More than $75 \%$ of less developed countries use medicinal plants for their primary health care needs due to economic reasons (Jamshidi-Kia et al., 2018). Nigella sativa (NS), known as black seed, is a supernatural occurring herb that grows once a year, in Europe, Middle East and Western Asia and belongs to the herbal family of Ranunculaceae with a wide range of pharmacological potential. Clinical and animal studies have demonstrated that NS extracts show many therapeutic impacts such as antidiabetic, antibacterial, antifungal, antiinflammatory, immunomodulatory, hepatoprotective, nephroprotective, gastroprotective and antitumor (Mohammed and Al-Suwaiegh, 2016; Farooqui et al., 2017; Elseweidy et al., 2018; Hosseinian et al., 2018; AboSaleh et al., 2019). Based on both in-vivo and in-vitro studies, the vast majority of these pharmacological effects are due to their antioxidant activity which is for the most part due to its ability of salvaging free radicals and/or hindering lipid peroxidation (Ozdemir et al., 2018). In addition, NS oil secures kidney tissue against oxygen free radicals, preventing renal dysfunction and pathological changes (Saadia et al., 2019).

\section{AIM OF THE WORK}

This study was conducted to evaluate possible protective effects of atorvastatin and/or Nigella Sativa in rat model of amikacininduced nephrotoxicity.

\section{MATERIALS AND METHODS}

The present experiment was conducted in Faculty of Medicine- King Abdulaziz University, Jeddah, Saudi Arabia.

Test Materials:

- Amikacin (Amikacin®) 500mg/2ml vial, Amoun Pharmaceutical Co. (Cairo, Egypt).

- Atorvastatin (Lipitor ${ }^{\circledR)}$ tablets, Pfizer Saudi Limited, Saudi Arabia.

- Black seed oil, Nahdi Medical Company, Jeddah, Saudi Arabia.

Animals:

Random-bred, male albino rats (Wister strain), 200-240 gms were acclimatized for 7 days prior experimentation, housed in stainless steel wire mesh cages with wood chips as a bedding. Temperature was kept at $24 \pm 1^{\circ} \mathrm{C}$ on a light/dark cycle of $12 / 12$ hours and supplied rat chow and freshwater ad libitum.

This study was led according to the guidelines for dealing with experimental animals of the Biomedical Ethics Research Committee, Faculty of Medicine, King Abdulaziz University, Jeddah, Saudi Arabia (Reference No 92-20).

\section{Experimental Design:}

According to previous studies and after one-week adaptation period, rats were randomly and equally sorted into 5 experimental groups, 7 rats each. Sample size was estimated according to Jones et al (2004). Equivalent doses for adult male rat were calculated by using Paget and Barnes (1964):

- Group I (GI) $\rightarrow$ daily subcutaneous injection of $1 \mathrm{ml}$ isotonic saline for 2 weeks (ve control group).

- Group II (GII) $\rightarrow$ daily subcutaneous injection of $30 \mathrm{mg} / \mathrm{kg}$ AMK (double the therapeutic dose) for 2 weeks (Brunton et al., 2006). 
- Group III (GIII) $\rightarrow$ daily dose of ATO (dissolved in $500 \mu \mathrm{l}$ of $0.9 \%$ normal saline at a dose of $5 \mathrm{mg} / \mathrm{kg}$ by gavage) for 2 weeks with AMK (Panonnummal et al., 2013).

- Group IV (GIV) $\rightarrow$ daily dose of NS oil - $400 \mathrm{mg} / \mathrm{kg}$ (corresponding to $0.46 \mathrm{ml} / \mathrm{kg}$ ) by gavage - for 2 weeks with AMK (Fararh et al., 2002).

- Group V (GV) $\rightarrow$ AMK, ATO and NS oil in the same previously mentioned doses for 2 weeks.

At the end of the experiment, rats were anesthetized with $100 \mathrm{mg} / \mathrm{kg}$ ketamine and $10 \mathrm{mg} / \mathrm{kg}$ xylazine. Blood samples from the retro-orbital plexus of veins using a microcapillary tube were collected into clean centrifuge tubes. Animals were then euthanized with intraperitoneal injection with sodium pentobarbital. Kidneys were dissected; right kidneys were maintained in $10 \%$ buffered formaldehyde for histopathological study and left ones were homogenized in ice-cold isotonic saline for assessment of oxidative stress biomarkers.

\section{Serum biochemical parameters:}

\section{Tissue biomarkers of oxidative stress}

Kidney homogenate was used for lipid peroxidation products as well as antioxidant assays according to:

- Lipid peroxidation in renal tissues

(Mihara and Uchiyama, 1978).

- Glutathione (GSH) (Ellman, 1959).

- Catalase (CAT) activity (Aebi, 1984).

\section{Histopathology}

Kidney sections were fixed in $10 \%$ formalin and embedded in paraffin. Microtome sections were stained with hematoxylin and eosin ( $\mathrm{H} \& \mathrm{E})$ (Drury and Wallington, 1980).

\section{Statistical analysis:}

Performed using SPSS package (version 22). Results are expressed as means \pm SEM (standard error of mean) and analysed by oneway analysis of variance (ANOVA) followed by Dunnett's post hoc test. P-values $<0.05$ were taken to be statistically significant.

\section{Biochemical findings}

\section{RESULTS}

Serum creatinine, urea and BUN levels are shown in Table 1. Statistically significant increase was observed in the serum creatinine level in the AMK group $(\mathrm{p}<0.001)$ compared to the control. Treatment with ATO, NS oil or combination of both showed significant decrease $(p<0.05, \quad p<0.01$ and $p<0.001$ respectively) of serum creatinine as compared to AMK group (Table-1). Regarding serum urea and blood urea nitrogen levels, statistically significant increase was observed in the AMK $(\mathrm{p}<0.001)$ as compared to the control group. Treatment with NS oil alone or combined with ATO showed significant decrease of serum urea $(p<0.01$ and $p<0.001$ respectively) and blood urea nitrogen ( $p<0.01$ and $p<0.001$ respectively) as compared to AMK group. On the other hand, ATO alone did not significantly improve serum urea and blood urea nitrogen levels (Table-1).

MDA, GSH and CAT levels in kidney tissues are shown in Table 2. In AMK group, MDA concentration revealed significant increase $(p<0.01)$ as compared to the control. Treatment with NS oil alone or combined with ATO showed significant decrease $(p<0.05$ and $p<0.01$ respectively) of MDA concentration as compared to AMK group. Contrarily, ATO alone did not significantly decrease MDA level (Table-2). Considering GSH and CAT concentrations, AMK group showed significant decrease $(p<0.001)$ as compared with control group. Rats treated with NS oil alone or combined with ATO showed significant increase $(\mathrm{p}<0.05$ and $\mathrm{p}<0.01$ respectively) as compared to AMK group. In contrast, ATO alone did not significantly improve GSH and CAT concentrations (Table-2).

\section{Histopathological Findings}

Normal kidney sections were apparent in the negative control group (Group I) with thin glomerular basement membrane, normal cellularity and normal proximal and distal convoluted tubules (Figure 1A). AMK injection (Group II) produced renal tubular cellular necrosis, cellular debris and inflammatory exudates within the lumens of renal tubules (Figures 1B and C). Amikacininsulted rats treated with ATO (Group III), NS oil (Group IV) or both (Group V) showed signs of improvement seen in the cortex and Bowman's space. This improvement was 
slight in group III and best seen in Group V

(Figures $1 \mathrm{D}, \mathrm{E}$, and F).

Table-1: Mean values of kidney function tests in the studied groups.

\begin{tabular}{|l|c|c|c|}
\hline & $\begin{array}{c}\text { Creatinine } \\
(\mathrm{mg} / \mathrm{dl})\end{array}$ & $\begin{array}{c}\text { Urea } \\
(\mathrm{mg} / \mathrm{dl})\end{array}$ & $\begin{array}{c}\text { BUN } \\
(\mathrm{mg} / \mathrm{dl})\end{array}$ \\
\hline Group I (negative control) & $0.562 \pm 0.012$ & $19.51 \pm 0.18$ & $10.12 \pm 0.11$ \\
\hline Group II (Amikacin) & $1.408 \pm 0.042 \# \# \#$ & $52.12 \pm 0.61 \# \# \#$ & $22.67 \pm 0.25 \# \# \#$ \\
\hline Group III (Atorvastatin) & $1.272 \pm 0.045^{*}$ & $46.07 \pm 1.1$ & $21.54 \pm 0.68$ \\
\hline Group IV (Black seed oil) & $0.822 \pm 0.024 * *$ & $30.87 \pm 0.97 * *$ & $15.14 \pm 0.52^{* *}$ \\
\hline $\begin{array}{l}\text { Group V (both Atorvastatin } \\
\text { and Black seed oil) }\end{array}$ & $0.631 \pm 0.007 * * *$ & $20.65 \pm 0.65^{* * *}$ & $9.01 \pm 0.34 * * *$ \\
\hline
\end{tabular}

BUN: blood urea nitrogen

Data are presented as mean \pm standard error of the mean (SEM).

\#\#\# p<0.001 as compared to Group I; ${ }^{*} \mathrm{p}<0.05,{ }^{* *} \mathrm{p}<0.01$ and ${ }^{* * *} \mathrm{p}<0.001$ as compared to Group II.

Table-2: Lipid peroxidation and antioxidant status in kidneys of the studied groups

\begin{tabular}{|l|c|c|c|}
\hline & $\begin{array}{c}\text { MDA } \\
(\mathrm{nmole} / \mathrm{g} \text { tissue })\end{array}$ & $\begin{array}{c}\text { GSH } \\
(\mu \mathrm{g} / \mathrm{g} \text { tissue })\end{array}$ & $\begin{array}{c}\text { CAT } \\
(\mu \mathrm{g} / \mathrm{sec} / \mathrm{g} \text { tissue })\end{array}$ \\
\hline Group I (negative control) & $192.9 \pm 43.15$ & $3.616 \pm 0.366$ & $2.998 \pm 0.466$ \\
\hline Group II (Amikacin) & $496.9 \pm 75.7 \# \#$ & $\begin{array}{c}0.9066 \pm \\
0.255 \# \# \#\end{array}$ & $0.6312 \pm 0.184 \# \#$ \\
\hline Group III (Atorvastatin) & $408.4 \pm 61.43$ & $1.133 \pm 0.371$ & $0.8963 \pm 0.274$ \\
\hline Group IV (Black seed oil) & $275 \pm 49.22^{*}$ & $2.204 \pm 0.381 *$ & $1.457 \pm 0.181^{*}$ \\
\hline $\begin{array}{l}\text { Group V (both Atorvastatin and } \\
\text { Black seed oil) }\end{array}$ & $201.8 \pm 49.43^{* *}$ & $2.804 \pm 0.496^{* *}$ & $2.366 \pm 0.254 * *$ \\
\hline
\end{tabular}

MDA: malondialdehyde

GSH: reduced glutathione

CAT: catalase

Data are presented as mean \pm standard error of the mean (SEM).

\#\# p<0.01, \#\#\# p<0.001 as compared to Group I; ${ }^{*} \mathrm{p}<0.05$ and ${ }^{*} \mathrm{p}<<0.01$ as compared to Group II. 

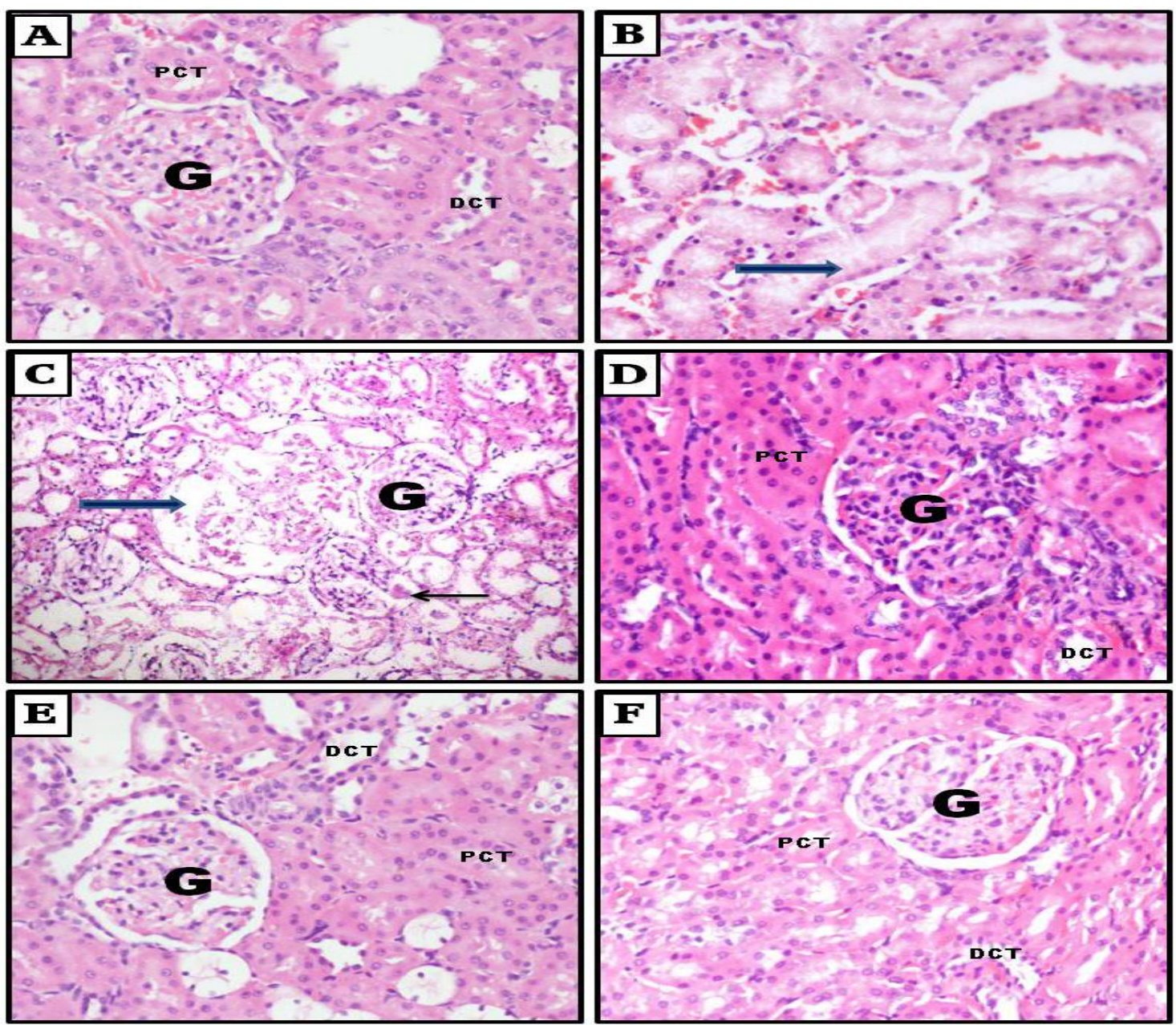

\section{Figure (1)}

(A) A photomicrograph of a section in rat kidney from group 1 showing the normal glomeruli $(G)$, proximal convoluted tubules (PCT) and distal convoluted tubules (DCT). (H\&E 200X). (B) A photomicrograph of a section in rat kidney from group II showing necrotic epithelial cells in the lumens of renal tubules (arrows) (H\&E 200X). (C) A photomicrograph of a section in rat kidney from group II showing tubular dilatation (thick arrow), and intratubular casts (translucent arrows) and intratubular casts (thin arrow) (H\&E 100X). (D) A photomicrograph of a section in rat kidney from group III showing cloudy swelling of the lining epithelial cells of some convoluted tubules with narrowing lumens. (H\&E 200X). (E) A photomicrograph of a section in rat kidney from group IV showing mild disruption of proximal (PCT) and distal (DCT) tubules with some degenerated cells (H\&E 200X). (F) A photomicrograph of a section in rat kidney from group $\mathrm{V}$ showing regeneration of proximal and distal convoluted tubules (H\&E 200X).

\section{DISCUSSION}

Because of its unmistakable role in major excretory pathways, the kidney is especially vulnerable to toxicity from aminoglycosides (AGs). Storage of AGs in the renal cortex affects renal function, and when reabsorbed by renal tubules they induce nephrotoxicity (Souza et al., 2009). Incidence of renal toxicity from AGs has exaggerated from 2$3 \%$ in 1969 to $20 \%$ in the past decades. This exaggeration may be attributed to the wider use of aminoglycosides due to the progressive development of resistance of gram-negative organisms to beta-lactam antibiotics and fluoroquinolones (Panonnummal et al., 2013). Although the precise mechanism of AG-induced nephrotoxicity -including amikacin which is the most widely used semisynthetic aminoglycoside- is not completely understood, there is much in-vivo and in-vitro proof that the production of free oxygen radicals may be involved in the pathogenesis of AG-induced renal injury (Ozbek et al., 2009 \& Abdel-Daim et al., 
2019). As amikacin-induced nephrotoxicity may be attributed to oxidative stress, antioxidant agents would possibly be valuable in resisting amikacin nephrotoxicity. Accordingly, the present study was set out with the aim of assessing the protective effect of Atorvastatin and/or black seed oil in amikacin-induced renal toxicity in albino rats.

Similar to previous reports (Yaman and Balikci, 2010 \& Hasanvand et al., 2020), results obtained in this study showed that rats exposed to amikacin $(30 \mathrm{mg} / \mathrm{kg}$ b.w./day, subcutaneously for 2 weeks) revealed significant increase in the mean values of serum creatinine, urea and BUN. Creatinine is regarded as one of the foremost reliable indicators of renal function efficiency especially in early stages of kidney disease (Babu et al., 2011). Conversely, urea concentrations start increasing only after parenchymal injury (Gilbert et al., 1989).

In the contemporary study, amikacin resulted in significant increase in malondialdehyde (MDA), the end-product of lipid peroxidation, and significant decrease in Glutathione (GSH) content and Catalase (CAT) activities when compared with the negative control group. Glutathione and catalase protect cells against toxic impacts of lipid peroxidation and their depletion is considered as a marker of oxidative stress (Rao and Shaha, 2001). These results corroborate the findings of a large volume of published studies which highly recommended the role of reactive oxygen species (ROS) in the renal tubular effects of aminoglycosides (Martínez-Salgado et al., 2004; Parlakpinar et al., 2006; Abdel-Daim et al., 2019). Through their properties as second messengers and inducers of oxidative stress, ROS role is increasingly more ostensible in mesangial cell impairment (MartínezSalgado et al., 2007).

In accordance with biochemical results in the current study, amikacin created various histological alterations mostly in renal tubules. It is therefore likely that a relatively higher load of amikacin reaches the cortex via the bloodstream than that entering the medulla. These findings broadly support the work of other studies (Vecchi et al., 1998; Zahid et al., 2007 \& Bulut et al., 2016). The present study reported the absence of glomerular changes as the toxic effects of aminoglycosides are mainly tubular. Similar results were also described by Bulut and coworkers (2016). However, Vecchi and coworkers (1998) revealed focal thrombosis of renal vessels along with congestion. Zahid and his colleagues (2007) demonstrated glomerular focal hypercellularity and congestion.

On the other hand, administration of atorvastatin $(5 \mathrm{mg} / \mathrm{kg} / \mathrm{day}$, by gavage for 2 weeks), black seed oil (400 $\mathrm{mg} / \mathrm{kg} / \mathrm{day}$, by gavage for 2 weeks) and both together has showed significant decrease in serum creatinine as compared to amikacin group in the current study. Black seed oil alone and in combination with atorvastatin showed significant decrease in serum urea and serum BUN as compared to amikacin group. In accordance, the present study showed that black seed oil administration alone and in combination with atorvastatin showed significant decrease in MDA and an increase in GSH and CAT activities as compared to amikacin group. Histopathological evaluation supports biochemical investigations. Atorvastatin rectified serum creatinine but failed to deliver any significant improvement in oxidative stress and antioxidant parameters altered by amikacin use. However, findings of the current study do not support the previous research of Ozbek and his colleagues (2009) who confirmed normalisation of Kidney function tests and tissue oxidative stress parameters in the gentamicin + atorvastatin $(10 \mathrm{mg} / \mathrm{kg} /$ day) group. A possible explanation for this inconsistency in the outcome is using higher dose of atorvastatin. Another study by Jaikumkao and co-workers (2016) showed a significant decrease of MDA levels in the kidneys of the atorvastatin-treated rats (10 $\mathrm{mg} / \mathrm{kg} /$ day) in gentamicin-induced nephrotoxicity. What is surprising is that, the decreased MDA level was greater with atorvastatin pre-treatment than atorvastatin post-treatment. It can therefore be assumed that the preventive effect of atorvastatin on oxidative stress was more effective than the post-treatment. This outcome is contrary to that of another study which reached the conclusion that atorvastatin $(10 \mathrm{mg} / \mathrm{kg} / \mathrm{day}$, 
p.o.) could not reduce renal ROS, MDA, serum urea and creatinine levels in gentamicin-induced nephrotoxicity in rats (Mehrzadi et al., 2016). Panonnummal and his colleagues (2013) assumed that the protective effect awarded by atorvastatin against vancomycin-induced nephrotoxicity was dose dependent. A dose of $10 \mathrm{mg} / \mathrm{kg} /$ day secured ideal safety by restoring the antioxidant status. Interestingly, a higher dose of $20 \mathrm{mg} / \mathrm{kg} /$ day exhibited reasonable degree of antioxidant activity but could not provide a protective effect. This rather contradictory result may be due to direct renal damage associated with this dose. Our approach to use a low dose of atorvastatin in the current study would further reduce the hazard of harmful effects. Additionally, it would still provide a placebo effect, if present, and alleviate the ethical issues concerning the use of placebos. Several authors suggested return of placebos to clinical practice (McCormack et al., 2011).

Statins decrease lipoprotein oxidation and ameliorate free radical injury, where atorvastatin shows significant antioxidant activity against hydroxide and peroxyl radicals. Besides, atorvastatin metabolites reduce lipoprotein oxidation in many oxidative systems (Ozbek et al., 2009). In general, there are two statin groups, lipophilic and hydrophilic. Atorvastatin, lovastatin, and simvastatin are relatively lipophilic, while pravastatin and rosuvastatin are hydrophilic. The two groups differ in the chemical structure and hydrophilic/lipophilic properties, resulting in differences in pharmacokinetics and pharmacodynamics, as well as pleiotropic effects (Kim et al., 2011). A recent study demonstrated the superiority of lipophilic atorvastatin to hydrophilic rosuvastatin in ameliorating renal injury parameters in rats (Jabarpour et al., 2020). This finding is contrary to the study by McWilliam and his colleagues (2020) which suggested that rosuvastatin is "the most promising candidate" among statins based upon its pharmacology.

The present study signalizes also the antioxidative potential of Nigella sativa oil that may protect the kidney against amikacininduced oxidative toxicity. This protective effect might be attributed, at least in part, to its ability to remove the reactive oxygen species that cause tissue damage, and to enhance DNA and protein synthesis essential for tissue regeneration (Yimer et al., 2019). Most therapeutic properties are due to the thymoquinone (TQ) content of this plant, a major active chemical component of the essential oil (Al-Ali et al., 2008). Yimer and co-workers (2019) suggested using Nigella sativa as essential nutrients for life for health promotion and diseases fighting for its marked antioxidant activity. A recent study reported that combining $N$. sativa with different conventional chemotherapeutic agents cause synergistic effects with the consequent reduction of the dose of the concomitantly used medicines and optimizing efficacy versus toxicity (Yimer et al., 2019).

The present results broadly support the work of other studies in this area linking Nigella sativa with kidney protection. Saleem and colleagues (2012) revealed that black seed oil lowered the values of serum creatinine, blood urea nitrogen and antioxidant activity as compared to gentamicin control group values. In addition, it has been reported that NS extract prevented the alteration in kidney pathology result from monosodium glutamate (MSG) which nearly return to their normal texture (Moussa and Al Mulhim, 2013). Furthermore, Majeed and Tahir (2014) demonstrated that Nigella sativa co-administration with amphotericin B $(\mathrm{AmB})$ significantly reduced serum urea and creatinine, indicating considerable protection afforded by Nigella sativa extract. However, when mice were given NS extract after the period of treatment with $\mathrm{AmB}$, the toxic effects of the drug persisted thus indicating that NS did not reverse the toxic effects produced earlier by the drug. Quadir and colleagues (2017) established that oral administration of $n$-hexane extract of Nigella sativa produced appreciable amendment from the nephrotoxic action of gentamicin in rats. A more recent study showed that Nigella sativa extract at 100 and $200 \mathrm{mg} / \mathrm{kg}$ in preventive and preventive + treatment groups combined with Vitamin E were able to improve renal tissue impairment and 
oxidative stress caused by cisplatin in the rat kidney. (Hosseinian et al., 2018)

In conclusion, based on the results obtained from the present study, we can infer that atorvastatin and black seed oil administered together can protect against amikacin nephrotoxicity. Co-administration of both drugs is more valuable than the intake of either of them alone. We used lower doses of atorvastatin than previous similar studies and this would further decrease the risk of adverse effects. This may be valuable for clinicians, especially on treating elderly patients.

\section{FUTURE RESEARCH WORK:}

Additional studies on different dose schedules and time - intervals are required to gain the best results and to define the exact mechanism/s by which atorvastatin and/or black seed oil protect against amikacin induced renal toxicity.

\section{CONFLICT OF INTEREST STATEMENT}

The authors declare that they have no conflict of interest.

\section{REFERENCES}

Abdel-Daim, M.M.; Ahmed, A.; Ijaz, H.; Abushouk, A.I.; Ahmed, H.; Negida, A.; Aleya, L. and Bungau, S.G. (2019): Influence of Spirulina platensis and ascorbic acid on amikacin-induced nephrotoxicity in rabbits. Environ. Sci. Pollut. Res., 26:8080-8086.

AboSaleh, S.; Salama, M.F.; El-Sherbini, E and Hassan, M.Z. (2019): The Possible Ameliorative Effect of Nigella Sativa on Aflatoxin-induced Liver Damage in Chicken. A.J.V.S. 63 (2): 113-120.

Aebi, H. (1984): Catalase methods of enzymatic analysis. In: Bergmeyer, H.U.(Ed.), Chemic, vol. 2. Academic Press Inc., New York, London, pp: 673677.

Al-Ali, A.; Alkhawajah, A.A.; Randhawa, M.A. and Shaikh, N.A. (2008): Oral and intraperitoneal LD50 of thymoquinone, an active principle of Nigella sativa, in mice and rats. J. Ayub. Med. Coll. Abbottabad, 20(2): 25-27.

Babu, S.V.; Urolagin, D.K.; Veeresh, B. and Attanshetty, N. (2011): Anogeissus latifolia prevents gentamicin induced nephrotoxicity in rats. Int. J. Pharm. Sci., 3 (1): 1091-1095.

Brunton, L. L.; Lazo, G. S. and Parker, K. L. (2006): In: Goodman \& Gilman's. The Pharmacological Basis of Therapeutics. Mc Graw-Hill Inc., 11th ed., P.P.11551167.

Bulut, G.; Basbugan, Y.; Ari, E.; Erten, R.; Bektas, H.; Alp, H.H. and Bayram, I. (2016): Paricalcitol may improve oxidative DNA damage on experimental amikacin-induced nephrotoxicity model. Ren. Fail., 38(5):751-758.

Drury, R.A. and Wallington, E.A. (1980): Carleton's Histological Techniques, $5^{\text {th }}$ ed., Oxoford Univ. Press, London, New York, Toronto, p.p: 241-242.

Ellman, G.L. (1959): Tissue sulfhydryl groups. Arch. Biochem. Biophys., 82:7073.

Elseweidy, M.M.; Amin, R.S.; Atteia, H.H.and Aly, M.A. (2018): Nigella sativa oil and chromium picolinate ameliorate fructose-induced hyperinsulinemia by enhancing insulin signaling and suppressing insulindegrading enzyme in male rats. Biol. Trace Elem. Res., 184:119-126.

Fararh, K.M.; Atoji, Y.; Shimizu, Y. and Takewaki, T. (2002): Isulinotropic properties of NSO in Streptozotocin plus Nicotinamide diabetic hamster. Res. Vet. Sci., 73: 279-282.

Farooqui, Z.; Ahmed, F.; Rizwan, S.; Shahid, F.; Khan, A. and Khan, F. (2017): Protective effect of Nigella Sativa oil on cisplatin induced nephrotoxicity and oxidative damage in rat kidney. Biomedicine \& Pharmacotherapy, 85: 7-15.

Gilbert, D.N..; Wood, C.A. and Kohlhepp, S.J. (1989): Polyaspartic acid prevents experimental aminoglycoside nephrotoxicity. J. Infect. Dis.,159: 945953.

Hasanvand, A.; Tavafi, M.; Ahmadvand, H. and Tamjidipoor, A. (2020): Effect of dimethyl sulfoxide in combat with gentamicin induced nephrotoxicity in rats. J. Nephropathol., 9(1): 1- 6.

Hosseinian, S.; Roshan, N. M.; Khazaei, M.; Shahraki, S.; Mohebbati, R. and 
Rad, A. K. (2018): Renoprotective Effect of Nigella sativa against Cisplatininduced Nephrotoxicity and Oxidative Stress in Rat. Saudi J. Kidney Dis. Transpl., 29(1): 19-29.

Jabarpour, M.; Rashtchizadeh, N.; Ghorbani, A.; Argani, H.; Nemati, M.; Dastmalchi, S.; Roshangar, L.; Ranjbarzadhag, M.; Bargahi, N. and Sanajou, D. (2020): Protection of renal damage by HMG-CoA inhibitors: A comparative study between atorvastatin and rosuvastatin. Iran. J. Basic Med. Sci., 23 (2): $206-213$.

Jadhav, R.W.; Al-Kobaisi, M.; Jones, L.A.; Vinu, A. and Bhosale, S.V. (2019): the supramolecular self-assembly of aminoglycoside antibiotics and their applications. Chemistry Open. https://doi.org/10.1002/open.201900193.

Jaikumkao, K.; Pongchaidecha, A.; Chattipakorn, N.; Chatsudthipong, V.; Promsan, S.; Arjinajarn, P. and Lungkaphin, A. (2016): Atorvastatin improves renal organic anion transporter 3 and renal function in gentamicininduced nephrotoxicity in rats. Exp. Physiol., 101(6): 743-753.

Jamshidi-Kia, F; Lorigooini, Z. and AminiKhoei, H. (2018): "Medicinal plants: Past history and future perspective". J. Herbmed. Pharmacol., 7(1): 1-7.

Jones, S.R.; Carley, S. and Harrison, M. (2003): An introduction to power and sample size estimation. Emerg. Med. J., 20(5): 453-458.

Kim, M.C.; Ahn, Y.; Jang, S.Y.; Cho, K.H.; Hwang, S.H. and Lee, M.G. (2011): Comparison of clinical outcomes of hydrophilic and lipophilic statins in patients with acute myocardial infarction. Korean J. Intern. Med., 26:294-303.

Majeed, N. and Tahir, M. (2014): Effect of Nigella sativa extract on renal functions in amphotericin B induced nephrotoxicity in mice. Biomedica, 30(1): 1-4.

Martínez-Salgado, C.; Eleno, N.; Morales, A.; Pérez-Barriocanal, F.; Arévalo, M. and López-Novoa, J.M. (2004): Gentamicin treatment induces simultaneous mesangial proliferation and apoptosis in rats. Kidney Int., 65: 21612171.

1. Martinez-Salgado, C.; LopezHernandez, F.J. and Lopez-Novoa, J.M. (2007): Glomerular nephrotoxicity of aminoglycosides. Toxicol. Appl. Pharmacol., 223: 86-98.

McCormack, J.P.; Allen, G.M. and Virani, A.S. (2011): Is bigger better? An argument for very low starting doses. CMAJ., 183: 65-69.

McWilliam, S.J.; Rosala-Hallas, A.; Jones, A.P.; Shaw, V.; Greenhalf, W.; Jaki, T.; Smyth, A.R. and Pirmohamed, M. (2020): A randomised controlled trial of rosuvastatin for the prevention of aminoglycoside-induced kidney toxicity in children with cystic fibrosis. Sci. Rep. 10, 1796. https://doi.org/10.1038/s41598020-58790-1

Mehrzadi, S.; Kamrava, S.K.; Dormanesh, B.; Motevalian, M.; Hosseinzadeh, A.; Hosseini Tabatabaei, S.M. and Ghaznavi, H. (2016): Melatonin synergistically enhances protective effect of atorvastatin against gentamicininduced nephrotoxicity in rat kidney. Can. J. Physiol. Pharmacol., 94(3): 265271.

Mihara, M. and Uchiyama, M. (1978): Determination of malonaldehyde precursor in tissues by thiobarbituric acid test. Anal. Biochem., 86: 271-278.

Mohammed, A.A. and Al-Suwaiegh, S.B. (2016): Effects of Nigella sativa on mammals' health and production. Adv. Anim. Vet. Sci., 4: 630-636.

Moussa, E.A. and Al Mulhim, J.A.A. (2013): Modulating effect of Nigella sativa on renal structural changes by monosodium glutamate in female mice. Egypt. Acad. J. Biolog. Sci., 5(2): 33-45.

Ozbek, E.; Cekmen, M.; Ilbey, Y.O.; Simsek, A.; Polat, E.C. and Somay, A. (2009): Atorvastatin prevents gentamicin-induced renal damage in rats through the inhibition of p38-MAPK and NF-kappaB pathways. Ren. Fail., 31(5): 382-392.

Ozdemir, N.; Kantekin-Erdogan, M.N.; Tat, T. and Tekin, A. (2018): Effect of black cumin oil on the oxidative stability 
and sensory characteristics of mayonnaise. J. Food Sci. Technol., 55 (4): 1562-1568.

Paget, G. C. and Barnes, J. M. (1964): "Toxicity in evaluation of the drug activities". Pharmacometric ed. Lournace and bacharachai, Academic press, London and New York.; Pp: 1-13.

Panonnummal, R.; Varkey, J. and Dinoop, D. R. (2013): Are statins nephroprotective?: A dose dependant study in albino rats. Int. J. Pharm. Pharm. Sci., 5(3): 182-190.

Parlakpinar, H.; Koc, M.; Polat, A.; Vardi, N.; Ozer, M. K.; Turkoz, Y. and Acet, A. (2006): "Protective effect of aminoguanidine against nephrotoxicity induced by amikacin in rats". Cell Biochem. Funct., 24(4): 363-367.

Quadir, R.; Khan, M. I.; Eva, E.; Rahman, H.; Ahasan, F. and Hasan, M. J. (2017): The Effect of Nigella Sativa Linn (Kalajira) Extract on GentamicinInduced Nephrotoxicity in Experimental Rats. J. Dhaka Med. Coll., 25(2): 119123.

Rao, A.V. and Shaha, C. (2001): Multiple glutathione S-transferase isoforms are present on male germ cell plasma membrane. FEBS Lett., 507:174- 180.

Saadia, M.; Sher, M.; Bashir, S.; Murtaza, M.A.; Shah, A. and Khan, M.A. (2019): Comparative hepatoprotective effect of Nigella sativa pre- and post-treatment to rabbits. Pak. J. Pharm. Sci., 32(1): 205212.

Saleem, U.; Ahmad, B.; Rehman, K.; Mahmood, S.; Alam, M. and Erum, A. (2012): Nephro-protective effect of vitamin $\mathrm{C}$ and Nigella sativa oil on gentamicin associated nephrotoxicity in rabbits. Pak. J. Pharm. Sci., 25(4): 727730.
Soejima, A.; Ishizuka, S.; Miyake, N.; Fukuoka, K.;, Suzuki, M. and Kamiya, Y. (2000): Simultaneous inhibition of renal phospholipase $\mathrm{A}(2)$ and glutathione synthesis by manoalide and DLbuthionine sulfoximine induces acute tubular dysfunction in rats. Exp. Ephrol., 8 (2): 84-90.

Souza, V.B.; Oliveira, R.F.L.; Lucena, H.F.; Antunes, A.A.; Guerra, G.C.B. and Freitas, M.L. (2009): Gentamicin induces renal morphopathology in Wistar rats. Int. J. of Morphol., 27:59-63.

Swan, R.A. and Kaplan-Machlis, B. (1999): Therapeutic use of vita-min $\mathrm{E}$ in prevention of atherosclerosis. Altern. Med. Rev., 4 (6): 414-423.

Vecchi, E.D.; Lubatti, L. and Beretta, C. (1998): Protection from renal ischemia reperfusion injury by the 2-methylaminochroman U83836E. Kidney Int., 54: 857-863.

Wargo, K.A. and Edwards, J.D. (2014): Aminoglycoside-induced nephrotoxicity. J. Pharm. Pract. 27:573-577.

Yaman, I. and Balikci, E. (2010): Protective effects of Nigella sativa against gentamicin-induced nephrotoxicity in rats. Exp. Toxicol. Pathol., 62(2): 183190.

Yimer, E.M.; Tuem, K.B.; Karim, A.; UrRehman, N. and Anwar, F. (2019): Nigella sativa L. (Black Cumin): A Promising Natural Remedy for Wide Range of Illnesses. Evid. Based Complement. Alternat. Med., 6: 1-16.

Zahid, M.; Kamal, F.; Kamar, M. Z. Bhatti, S. A. and Insari, N. I. (2007): Morphological changes produced by aminoglycoside induced nephrotoxicityan experimental study. Annals, 13 (4): 234- 237. 
التأثير الوقائى المحتمل للأتورفاستاتين وزيت الحبة السوداء (نيجيلا ساتيفا) في التأثيرات السامة لعقار الأميكاسين على كلى

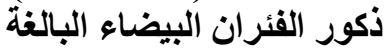

1,2 1أماني عبد الفتاح بيومي 1, إيمان فوزي جاب الله 1 ـخالد عبد الفتاح بيومي

قسم الطب الثرعي والسموم الإكلينيكيةـ كلية الطب - جامعة القاهرة- جمهورية مصر العربية.

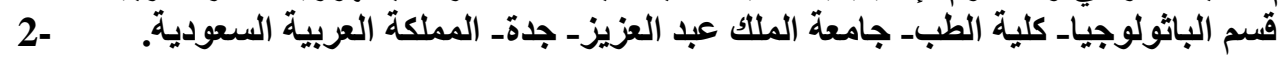

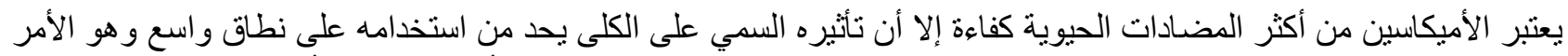

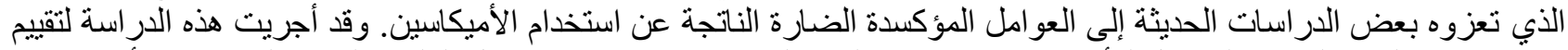

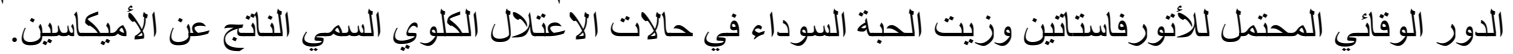

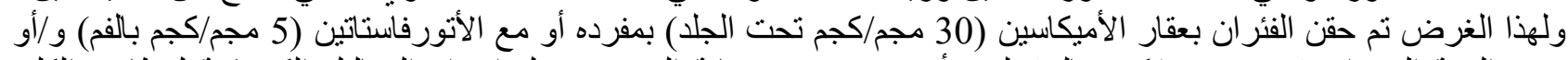

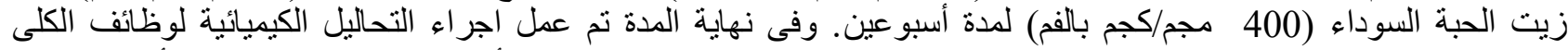

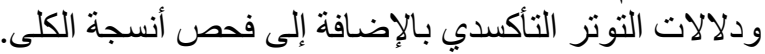

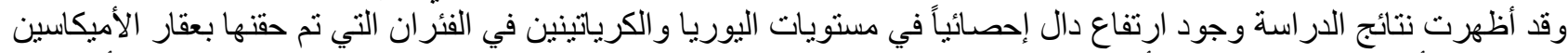

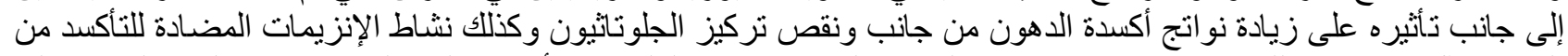

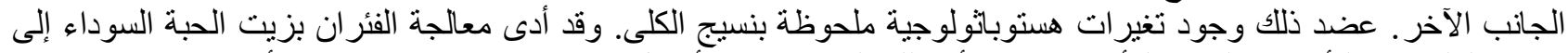

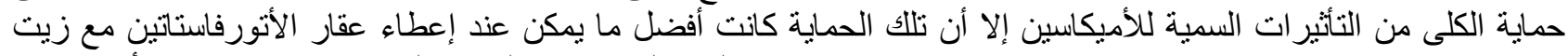

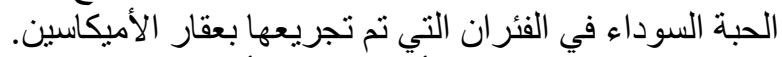

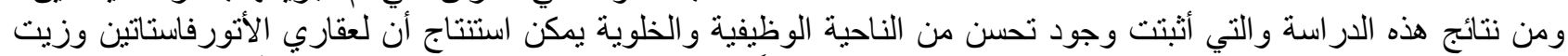
الحبة السوداء دور وقائي عند إعطائهما معاً ضد الاعنداء ولأل الكلوي السمي الناتج عن الأميكاسين في الفئران. 